\title{
DON QUIJOTE Y EL DIÁLOGO DE LA NOVELA
}

Referirse a Don Quijote resulta inevitable cuando se estudia el diálogo en los siglos XVI y XVII. En 1910, después de escribir que la «novela es la categoría del diálogo», Ortega y Gasset habla del Quijote como de "un conjunto de diálogos" '. Con posterioridad, en 1947, Eleazar Huerta comenta que el diálogo es la característica común a las mejores obras de Cervantes: Don Quijote, los ocho entremeses y El coloquio de los perros ${ }^{2}$. Luego añade:

La postura de Cervantes, ejemplar y desinteresada, es platónica, y platónico es, por lo mismo, su diálogo. Sus precedentes verdaderos hay que buscarlos - si nos ceñimos a nuestra literatura - en el Cortesano traducido por Boscán, el Diálogo de la lengua de Valdés, los Nombres de Cristo del maestro León ${ }^{3}$.

En este mismo sentido, Luis Andrés Murillo establece una relación de dependencia entre los diálogos del siglo XVI y la obra de Cervantes, en su tesis de 1953 todavía inédita, pero extractada de manera parcial en algunos artículos ${ }^{4}$. Con posterioridad, en 1981, Pablo Jauralde también asimila el diálogo del Quijote a esta tradi-

1 "Adán en el Paraíso", Personas, obras, cosas, en Obras Completas. Madrid, Revista de Occidente, 1966 ', vol. I, p. 489. En 1914, publica ORTEGA sus Meditaciones del "Quijote", ibid, pp. 309-400.

2 Además de los entremeses, El coloquio de los perros es la única obra en prosa de Cervantes escrita por entero en forma dialogada. Sin embargo, DANIEL EISENBERG ha vuelto a defender recientemente la autoría cervantina de un diálogo inédito, entre Cilenia y Selanio: Las "Semanas del Jardín" de Miguel de Cervantes. Salamanca, Diputación, 1988.

3 «El diálogo cervantinow, Atenea, XXIV, 1947, p. 66.

4 "The Spanish Prose Dialogue of the Sixteenth Century*, Diss. Harvard University, 1953. Los artículos son: "Diálogo y dialéctica en el siglo XVI español», Revista de la Universidad de Buenos Aires, IV, 1959, pp. 55-56, y "Cervantes' Coloquio de los perros, a Novel-Dialoguew, Modern Philology, LVIII, 1961, pp. 174 . 85. 
ción humanista ${ }^{5}$. Murillo había llegado a sugerir, como Eleazar Huerta, que el diálogo quijotesco es equivalente a la dialéctica platónica:

No se sitúan con facilidad los diálogos del Quijote en enlazada progresión con los de Platón. Y sin embargo son diálogos españoles por esencia como por esencia son diálogos griegos los de Platón; también la dialéctica hispánica de las geniales criaturas de Cervantes nació de la meditación moral y escéptica ante las verdades del presente y del pasado ${ }^{\circ}$.

Con este tipo de planteamientos se desplaza el problema desde el diálogo hacia la dialéctica. En 1979, Claudio Guillén se refiere a la «dialéctica, o el diálogo inacabado" del Quijote?. Y, en 1983, Elías L. Rivers escribe sobre la "Cervantine Dialectic" ${ }^{8}$. Diálogo y dialéctica, sin embargo, no son términos equivalentes. Como creo haber demostrado, la sustancia de los diálogos españoles del siglo XVI no es dialéctica, sino didáctica 9 . Es decir, se concibe el diálogo como un medio de transmisión del conocimiento, antes que como una búsqueda compartida de la verdad, según aparece en Platón.

En todo caso, no es conveniente asimilar de manera absoluta un medio de expresión formal (el diálogo, en este caso) a una determinada visión del mundo o a un método (dialéctico) de conocimiento. Por el contrario, el diálogo puede ser monológico, y viceversa: un discurso puede ser dialógico. De ahí se deduce la diferencia entre diálogo y dialogismo que ha puesto de relieve Mijail M. Bajtín, en sus estudios sobre la novela ${ }^{10}$. Cuando este

' «Los diálogos del Quijote: raíces e interpretación históricaw, en Instituto de Bachillerato "Cervantes". Miscelánea en su cincuentenario, 1931-81. Madrid, Ministerio de Cultura, 1981, pp. 181-93. Por su parte, August RÚEGg sostiene que Cervantes prolongó la tradición de los colloquia de Erasmo: «Lo erásmico en el Don Quijote de Cervantes*, $A C$, IV, 1954, pp. 1.40. En cambio, escribe MANUEL CP.IADO DE Val: «Don Quijote, como diálogow, AC, V, 1955-6, pp. 207-8: «La modalidad de los coloquios erasmistas tuvo en España una gran fortuna. Por otro camino, la cortesanía renacentista, asimismo dialogada, penetró profundamente en el gusto español. Pero, no necesitaba Cervantes de estos modelos para enlazar con la tradición coloquial de Castilla la Nueva, que desde Juan Ruiz había perfeccionado su técnica literaria. El Arcipreste de Talavera, Rodrigo Cota, Rojas y el anónimo autor del Lazarillo de Tormes, son los verdaderos precursores de este máximo coloquio que el Quijote representax.

- «Diálogo y dialécticaw, p. 66.

1. Cervantes y la dialéctica, o el diálogo inacabadow, en Les Cultures ibériques en devenir. Essais publiés en hommage à la mémoire de Marcel Bataillon. París, Fontation Singer-Polignac, 1979, pp. 631.45; reed. en El primer siglo de Oro. Estudios sobré géneros y modelos. Barcelona, Crítica, 1988, pp. 212-34.

- "Cervantine Dialecticn, Quixotic Scriptures. Essays on the Textuality of Hispanic Literature. Bloomington, Indiana University Press, 1984, pp. 105-31.

- El dialogo en el Renacimiento español Madrid, Cátedra, 1988.

10 Véase, por ejemplo, La Poétique de Dostoievski (1963), trad. fr. I. Kolitcheff. París, Seuil, 1970, y Teoría y estética de la novela (1979), trad. Helena S. Kriúkova y Vicente Cazcarra. Madrid, Taurus, 1989. Para la comprensión de las teorías de 
crítico habla de dialogismo se refiere a la novela moderna, sobre todo a partir de Dostoievski, y a procedimientos literarios muy diferentes del diálogo, como el llamado restilo indirecto librew. De este modo, una novela dialogada no tiene por qué ser más dialógica, en términos bajtinianos, que otra cualquiera ".

Además de las distinciones apuntadas entre diálogo, dialéctica y dialogismo, a la hora de estudiar el Quijote, hay que tener presente que existen varios tipos muy diferentes de diálogo, sobre todo el de la novela con respecto al diálogo didáctico. En términos genéricos, el diálogo de la novela es semejante al del teatro, pero opuesto al diálogo didáctico. La característica principal de este último tipo de diálogo estriba en que los interlocutores, el tiempo y el espacio están al servicio de las ideas que, a su vez, dependen del proceso discursivo (lógico o retórico) de la argumentación. Por el contrario, en el diálogo de la novela, las ideas tienden a depender de la caracterización individual de los interlocutores, orientados hacia la acción y determinados por una historia personal concreta, lo mismo que sucede en el teatro ${ }^{12}$.

El diálogo del Quijote se puede relacionar con el de la Celestina y con la tradición que continúa en el siglo XVI, tanto en la celestinesca como en los entremeses de Lope de Rueda que (no lo olvidemos) están escritos en prosa. A esta relación parece aludir Avellaneda cuando habla en términos despectivos de las novelas de Cervantes como de comedias en prosa. "Conténtese con su Galatea y comedias en prosa, que eso son las más de sus novelas, no nos canse" ${ }^{13}$. Por otra parte, escribe Menéndez Pelayo:

Bajtín, es útil el libro de TzVETAN TODOROv, Mikhail Bakhtine: le principe dialogique suivi des écrits du cercle de Bakhtine. Paris, Seuil, 1981.

"Las teorias de Bajtin aplicadas al hispanismo se han desarrollado, sobre todo, a partir de la década de los ochenta. Véase JAvier Huerta Calvo, «La teoría literaria de Mijail Bajtín. Apuntes y textos para su introducción en Españaw, Dicenda, I, 1982, pp. 143-58, y «El diálogo en el centro de la poética: Bajtín. Ensayo de una bibliografía crítica», Diálogos hispánicos de Amsterdam, VI, 1987, pp. 195. 218. Por lo que se refiere al dialogismo del Quijote, que es lo que aquí nos interesa, véase el artículo de MERCEDES GRACIA CALVO: «La embajada a Dulcinea: lectura bajtiniana*, $A C$, XXIII, 1985, pp. 97-115. FERNANDO LAZARO CARRETER, «La prosa del Quijoten, en Lecciones cervantinas, ed. Aurora Egido, Zaragoza, CAZAR, 1985, pp. 115-29. Y HORST WeICH: «Narración polifónica: el Quijote y sus seguidores franceses (siglos XVII y XVII)w, Anthropos, 98/99, 1989, pp. 107-12.

12 Ésta es la distinción expuesta en mi comunicación presentada en el II Congreso de la Asociación Internacional Siglo de Oro, celebrado en el mes de julio de 1990, entre Salamanca y Valladolid: aiálogo, texto dramático y teatro (siglo XVI)n. Comp. JACQUELINE SAvOYE: «Del diálogo humanistico a la novelaw, en Homenaje a Jose Antonio Maravall Madrid, Centro de Investigaciones Sociológicas, 1986, pp. 349-58. Y Stephen Gilman: «Cervantes en la obra de Mark Twain (Hacia una teoría del diálogo novelístico)», en Homenaje de "Insula" a Cervantes en el cuarto centenario de su nacimiento, 1547-1597. Madrid, Insula, 1945, pp. 207-22.

13 Don Quijote de la Mancha, ed. Martín de Riquer. Madrid, Espasa-Calpe, 1972, vol. I, p. 12. 
No de los novelistas picarescos, a cuya serie no pertenece, pero sí de la Celestina y de las comedias y pasos de Lope de Rueda, recibió Cervantes la primera iniciación en el arte del diálogo, y un tesoro de dicción popular, pintoresca y sazonada 14 .

Más recientemente, Anthony Close ha estudiado las características teatrales del Quijote y de otras novelas cervantinas, como Rinconete y Cortadillo ${ }^{15}$, que manifiestan una clara afinidad con la tradición del entremés, precisamente por su empleo del diálogo. En lo que se refiere al Quijote más en concreto, Close ${ }^{16}$ señala que las conversaciones entre don Quijote y Sancho se asemejan al esquema típico de la comedia, del galán con el gracioso, y cita para ilustrarlo algunos pasajes de Los Menemnos (1559) de Timoneda.

El diálogo del Quijote se acerca al diálogo teatral en la medida en que no es un diálogo objetivo, sino que depende de cada personaje, de acuerdo con su procedencia social o geográfica. Este es uno de los rasgos de la lengua cervantina que con más acierto ha subrayado la crítica, en el estudio clásico de Helmut Hatzfeld, o en el de Ángel Rosenblat '17. Don Quijote está caracterizado por su estilo caballeresco y arcaico, mientras que Sancho lo está por el suyo popular, plagado de refranes, modismos e incorrecciones lingüísticas. Por su parte, el bachiller Sansón Carrasco introduce latinismos cuando habla, el vizcaíno chapurrea el castellano, los galeotes hablan germanía, el capitán cautivo no puede evitar los arabismos, Zoraida se expresa en un pidgin hispanoarábigo, etc. La diversidad del universo novelístico del Quijote, habitado por multitud de personajes (659 para ser más exactos), tiene un reflejo evidente en su diversidad lingüística y dialógica, desde el nivel retórico más afectado hasta el habla coloquial ${ }^{18 .}$

14 "Cultura literaria de Miguel de Cervantes y elaboración del Quijoten, en Estudios y discursos de crítica histórica y literaria. Santander, CSIC, 1941, vol. I, p. 339. No olvidemos la decidida vocación teatral que manifiesta Cervantes, por ejemplo, en el prólogo a la edición de sus Ocho comedias y ocho entremeses.

15 "Characterization and Dialogue in Cervantes' comedias en prosa, MLR, LXXVI, 1981, pp. 338-56. Comp. Domingo YNDURÁIN: "Rinconete y Cortadillo. De entremés a novelan, BRAE, XLVI, 1966, pp. 321-33.

16 Art. cit., pp. 344 y ss. Por su parte, Francisco Márouez Villanueva ha estudiado el entronque de la figura de Sancho con la del gracioso de la comedia: "La génesis literaria de Sancho", Fuentes literarias cervantinas. Madrid, Gredos, 1973, pp. 20-95. comp. W. S. HendRIX: "Sancho Panza and the Comic Types of the Sixteenth Centuryn, en Homenaje ofrecido a Menéndez Pidal, Madrid, 1925, vol. II, pp. $485-94$.

17 Helmut Hatzfeld, El "Quijote" como obra de arte del lenguaje (1927),' trad. cast. Madrid, CSIC, $1966^{\prime}$, pp. 91-4; ÁNGEL ROSENBLAT, La lengua del "Quijote". Madrid, Gredos, 1971, pp. 205-6.

18 Pablo Jauralde («Los diálogos del Quijote», p. 188) distingue el «diálogo cortesano de los discretos, afectado, empalagoso y francamente literalizadon del "diálogo coloquial». Con posterioridad, ha estudiado esta misma variedad dialógica en las Novelas ejemplares: "Los diálogos de las Novelas ejemplarex, en Lenguaje, ideologia y organización en las "Novelas ejemplares". Madrid, Universidad Complutense, 1983, pp. 51-8. 
Según la "rueda virgiliana», cada personaje habla de acuerdo con su procedencia social, que se corresponde con la excelencia artística del poema: sublime en la Eneida, medio en las Geórgicas, bajo en las Bucólicas. La ruptura de esta convención estilística ha tenido consecuencias fundamentales en la historia de la literatura occidental, como ha estudiado Erich Auerbach ${ }^{19}$, quien, sin embargo, menosprecia el papel del Quijote en este proceso. En la obra maestra de Cervantes, se produce de manera significativa la parodia de la convención estilística que exige la correspondencia entre el habla de cada personaje y su condición social ${ }^{20}$. Así, Sancho intenta acceder con éxito relativo a un nivel lingüístico superior que, según el decoro o la "rueda virgiliana", no es el que le corresponde. Por ejemplo, cuando cree muerto a su amo tras de haber acometido la aventura de los disciplinantes, Sancho inicia un lamento fúnebre en el que comete errores evidentes, como el de calificar al Quijote de whumilde con los soberbios y arrogante con los humildes" ${ }^{21}$ :

- iOh flor de la caballeria, que con sólo un garrotazo acabaste la carrera de tus tan bien gastados años! jOh honra de tu linaje, honor y gloria de toda la Mancha, y aun de todo el mundo, el cual faltando tú en él, quedará lleno de malhechores, sin temor de ser castigados de sus malas fechoriasi !Oh liberal sobre todos los Alejandros, pues por solos ocho meses de servicio me tenias dada la mejor ínsula que el mar ciñe y rodea! ¡Oh humilde con los soberbios y arrogante con los humildes, acometedor de peligros, sufridor de afrentas, enamorado sin causa, imitador de los buenos, azote de los malos, enemigo de los ruines, en fin, caballero andante, que es todo lo que decir se puede! (I, 52).

La crítica se ha hecho eco de las frecuentes "prevaricaciones idiomáticas" 22, de Sancho, que trastueca el sonido de las palabras, sobre todo aquellas de procedencia culta o libresca: Catón Zonzorino por Censorino (I, 20), litado por dictado (I, 21), sobajada por soberana (I, 26 y 30), presonaje por personaje (II, 3), fócil por dócil (II, 7), revolcar por revocar (II, 7), sorbiese por asolviese (II, 8),

19 "La Dulcinea encantada», cap. 14 de Mimesis (1942), trad. cast. México, FCE, 1975, pp. 314-40.

20 Como apunta Alberto BlecuA («Cervantes y la retórica (Persiles, III, 17)» en Lecciones cervantinas, pp. 133-47), Cervantes se disculpa ya en el prólogo a la Galatea "por haber mezclado razones de filosofía entre algunas amorosas de pastores, que pocas veces se levantan a más que a tratar cosas del campow. La ruptura del decoro se justifica esta vez porque «muchos de los disfrazados pastores (...) lo eran sólo en el hábitow. La Galatea, ed. Juan Bautista Avalle-Arce. Madrid, Espasa-Calpe, 1968, vol. I, p. 8.

${ }^{21}$ Cito Don Quijote de la Mancha de Cervantes por la edición de Martín de Riquer. Barcelona, Planeta, $1980^{2}$, sin más que indicar entre paréntesis la parte que corresponde, en números romanos, y el capítulo, en arábigos.

22 Amado Alonso; «Las prevaricaciones idiomáticas de Sancho», NRFH, II, 1948, pp. 1-20; LeO SPITZER, «Perspectivismo lingüístico en el Quijoten, Lingüústica $e$ historia literaria Madrid, Gredos, 1974, pp. 141-4 y 151-8. Y ANGEL ROSENBLAT, ob. cit., pp. 33-5, 43-7 y 56-63. 
friscal por fiscal (II, 19), verde por verídico (II, 41). Latinismos: retencio por redemptio (I, 25), abernuncio por abrenuncio (II, 35). Nombres caballerescos: feo Blas por Fierabrás (I, 15), Malandrino, Malino y Martino por Mambrino (I, 19-21), Magimasa por Madásima (I, 25), abad por Elisabat (I, 25). En ocasiones, hay parlamentos enteros construidos sobre esta clase de equívocos:

...de cuando en cuando les decian: - iCaminad, trogloditas! - iCallad, bárbaros! - iPagad, antropófagos! - iNo os quejéis, scitas, ni abráis los ojos, Polifemos matadores, leones carniceros! (...) Sancho iba diciendo entre sí: $-i$ Nosotros tortolitas, nosotros barberos ni estropajos? ¿Nosotros perritas, a quien dice cita, cita? No me contentan nada estos nombres: a mal viento va esta parva (II, 68).

...o ya hemos pasado o pasaremos presto la línea equinoccial que divide y corta los dos contrapuestos polos en igual distancia. - Y cuando lleguemos a esa leña que vuesa merced dice - preguntó Sancho-, ¿cuánto habremos caminado? - Mucho - replicó don Quijote-; porque de trescientos y setenta grados que contiene el globo, del agua y de la tierra, según el cómputo de Ptolomeo, que fue el mayor cosmógrafo que se sabe, la mitad habremos caminado, llegando a la línea que he dicho. - Por Dios - dijo Sancho-, que vuesa merced me trae por testigo de lo que dice a una gentil persona, puto y gafo, con la añadidura de meón, o meo, no no sé cómo. Ríose don Quijote de la interpretación que Sancho había dado al nombre y al cómputo y cuenta del cosmógrafo Ptolomeo... (II, 29).

Como recurso humorístico, las prevaricaciones idiomáticas son frecuentes en el teatro del siglo XVI, por ejemplo en el de Lope de Rueda ${ }^{23}$. Aunque las prevaricaciones de Sancho no tienen sólo un valor cómico, sino que sirven para caracterizar al personaje como individuo ${ }^{24}$. A medida que avanza la novela, Sancho se apropia del ideal lingüístico del Quijote, aunque adaptado a su mentalidad rústica, como él mismo dice:

no hay para qué obligar al sayagués a que hable como el toledano, y toledanos puede haber que no las corten en el aire en esto del hablar polido (II, 19).

De este modo, no sólo se relativiza el paradigma del castellano, que era el habla de Toledo desde tiempos de Alfonso $\mathrm{X}$, sino que se derrumban los fundamentos de la teoría de los tres estilos.

"A. Alonso (art. cit., pp. 19-20, nota) cita algunos ejemplos de la Eufemia y de los Engañados. También de la Trofea y de la Soldadesca de Torres Naharro. Por otra parte, hay que tener en cuenta que las "prevaricaciones idiomáticas" casi nunca aparecen en el diálogo didáctico.

24 Como recuerda LAzARo CARRETER (art. cit., p. 127), la caracterización lingüística de Sancho es uno de los aciertos de Cervantes, que logró con ello un gran éxito. Asi le dice el bachiller Carrasco a Sancho que, al leer la primera parte del Quijote, whay tal que precia más de oiros hablar a vos que al más pintado de toda ellaw (II, 3). Además de que otros lectores, en espera de la segunda parte, exclaman: "Vengan más quijotadas: embista don Quijote y hable Sancho Panza" (II, 4). 
Según ilustra el propio Sancho, la discreción lingüística no es incompatible con la naturalidad ni con la baja condición social. De ahí los elogios que le prodigan los duques y don Quijote, sobre todo a propósito del episodio de la ínsula Barataria ${ }^{25}$. Sancho se ha "quijotizado" en su manera de hablar, como advierte su esposa nada más verle en el capítulo quinto de la segunda parte: «después que os hicistes caballero andante habláis de tan rodeada manera, que no hay quien os entienda" (II, 5). Incluso el fingido traductor de la obra se sorprende de manera irónica, al principio de este capítulo, puesto que men él habla Sancho Panza con otro estilo del que se podía prometer de su corto ingenion.

La inversión estilística se consuma en el caso de Sancho lo mismo que en el de don Quijote, aunque en sentido contrario. El ideal del caballero choca con la realidad de su tiempo, lo que se traduce en una serie de incoherencias lingüísticas. No sólo porque el modo de hablar del Quijote se contrapone con el de Sancho, en los frecuentes diálogos entre amo y escudero, o en los diálogos del amo con el ventero, el barbero, con las mozas de mesón, etc. El choque entre la realidad y el ideal se produce en el propio discurso del Quijote que, de este modo, queda dialogizado, en términos bajtinianos ${ }^{26}$. Así sucede, por ejemplo, en el relato de la cueva de Montesinos (II, 23), donde el sueño caballeresco del protagonista es distorsionado continuamente por sus obsesiones diurnas, desde una perspectiva desmitificadora ${ }^{27}$. El relato de la cueva de Montesinos no es un caso aislado ni se puede considerar como una excepción, por tratarse de un sueño. Como ha puesto de relieve Ángel Rosenblat ${ }^{28}$, don Quijote emplea en varias ocasiones vocablos procedentes del hampa y, en sus frecuentes accesos de ira, pierde su dignidad expresiva.

${ }^{25}$ Sancho se muestra siempre ingenioso en sus juicios como gobernador, excepto en el caso del supuesto «tejedor de hierros de lanzas», que se burla de él. Véase Michel MONER, «Le Dialogue comme structure ludique: Sancho et le 'tisseur de fers de lances' (Don Quichotte, II, 49)», en Essais sur le dialogue, ed. Jean Lavédrine. Grenoble, Université, 1980, pp. 79-98. Del mismo autor, Cervantes conteur. Écrits et Paroles. Madrid, Casa de Velázquez, 1989, p. 245.

26 A este propósito escribe Bajtín (Teoría y estética de la novela, p. 199) que «El objetivo intrínsecamente polémico de la palabra ennoblecida en relación con el plurilingüismo, aparecen [sic] Don Quijote en los diálogos novelescos con Sancho y otros representantes de la realidad plurilingüe y grosera de la vida, así como la dinámica misma de la intriga novelesca. El dialogismo interno potencial, que está en la base de la palabra ennoblecida, se ve aquí actualizado y evidenciado -en los diálogos y el movimiento de la intriga-; pero, al igual que en todo dialogismo lingüistico auténtico, no se agota definitivamente, ni se acaba desde el punto de vista dramático».

${ }^{27}$ Véase el estudio de AUrora EgIDo, «Cervantes y las puertas del sueño. Sobre la tradición erasmista del ultramundo en el episodio de la cueva de Montesinos", en Studia in honorem Prof. Martin de Riquer. Barcelona, Quaderns Crema, 1988, vol. III, pp. 305-41.

2s Ob. cit., pp. 206 y ss. 
La mezcla de estilos en Don Quijote es evidente, hasta tal punto que se utiliza no sólo como recurso humorístico, sino como medio privilegiado para caracterizar a los personajes en tanto que individuos. En este sentido, Cervantes es un fiel heredero del diálogo de la Celestina y de su conciencia dialógica, como ha estudiado Stephen Gilman ${ }^{29}$. El diálogo del Quijote no es uniforme, sino que depende del carácter de los personajes que, a su vez, varía según las particularidades de cada situación dialógica. Se trata, por tanto, de un diálogo subjetivo o, como dice Claudio Guillén, de un "diálogo inacabado»:

Las palabras revelan valores, pero jamás con independencia de las personas que las manifiestan, o mejor, de la vida que tales valores guian y que se confunden con ellos ${ }^{30}$.

Pero, a diferencia de lo que sucede en la Celestina, el diálogo entre los interlocutores del Quijote está filtrado por la figura del narrador ${ }^{31}$. Es decir, que hay dos diálogos diferentes: uno explícito, entre los interlocutores, y otro oculto entre las interlocuciones y la narración. Sólo desde esta perspectiva cabe estudiar la dialéctica y el dialogismo del Quijote, en términos bajtinianos ${ }^{32}$. Sin que por ello el dialogismo o la dialéctica se identifiquen de manera necesaria con el diálogo, como mecanismo de expresión formal.

El diálogo de Cervantes es dialéctico porque es dialéctica su visión del mundo, tal y como aparece en el estudio clásico de Américo Castro ${ }^{33}$. Y, lo que es más importante, esta dialéctica se traduce en una serie de aspectos del Quijote, además de en el diálogo: desde el "perspectivismo lingüístico» (Leo Spitzer) o desde los «enlaces abstracto-concretos» (Helmut Hatzfeld) hasta la mezcla

${ }^{29}$ La "Celestina": arte y estructura (1956), trad. Margit Frenk Alatorre. Madrid, Taurus, 1974, pp. 37-143.

$30 \quad$ Art. cit., p. 228.

31. S. Gilman insiste en esta diferencia, por ejemplo, La "Celestina": arte y estructura, pp. 90-91: "Vemos, pues, si en la Celestina el decoro no se funda nunca en la tercera persona y el diálogo goza en cambio de absoluta prioridad estilística, en el Quijote el autor ejerce una vigilancia irónica sobre el lenguaje hablado por la primera y segunda personas, supeditándolo a su propia visión cambiante. El decoro del 'padrastro' siempre presente puede contrastarse con el decoro radicalmente autónomo de la situación, como lo practicó y permitió Rojas».

32 BATJin, (por ejemplo, Teoría y estética de la novela, pp. 187 y ss.) siempre cita Don Quijote como ejemplo de novela polifónica, dialógica, paródica, etc., frente a lo que él llama las «novelas sofísticas» o monológicas: Las Etiópicas de Heliodoro, Las aventuras de Leucipa y Clitofonte de Aquiles Tacio o Dafnis y Cloe de Longo. Para la relación entre parodia y dialogismo véase CELINA S. DE CORTAZAR: «El Quijote, parodia antihumanista. Sobre la literatura paródica en la España barrocaw, AC, XXII, 1984, 59-75.

33 El pensamiento de Cervantes (1925), ed. Julio Rodríguez-Puértolas. BarcelonaMadrid, Noguer, 1980. 
de géneros literarios o la multiplicidad de narradores y de puntos de vista ${ }^{34}$.

Como la crítica ha destacado en más de una ocasión ${ }^{35}$, el realismo cervantino se opone al de la picaresca precisamente por su rechazo del punto de vista único. De ahí las ironías sobre el libro autobiográfico de Ginés de Pasamonte, en el episodio de los galeotes (I, 22), pues «¿Cómo puede ser acabado - respondió él-, si aún no está acabada mi vida?" Por boca del pícaro, Cervantes denuncia la imposibilidad de cerrar (en sentido artístico) una narración autobiográfica ${ }^{36}$. Además, como escribe Montaigne en uno de sus Essais (I, 19): "Qu'il ne faut juger de nostre heur qu'après la mort".

Al ser juez y parte, el pícaro no interpreta los hechos de manera imparcial, sino interesada y retóricamente, como hacen los galeotes cuando les interroga don Quijote ${ }^{37}$. La vida del pícaro se explica desde un solo punto de vista, y está predeterminada en una sola dirección. Por el contrario, los personajes del Quijote, como si fueran héroes adánicos ${ }^{38}$, construyen su destino mediante el libre albedrío y, en gran medida, al margen de sus circunstancias personales.

De todos modos, no conviene establecer una oposición total y constante entre la novela picaresca, el Guzmán de Alfarache en especial, y Don Quijote. Como ha estudiado Gonzalo Sobejano ${ }^{39}$, sería demasiado simple definir la obra de Mateo Alemán como un monólogo cerrado, contrapuesto al abierto diálogo del Quijote. Además de que, según hemos visto, no hay identificación absoluta entre el diálogo y una determinada visión del mundo. Diálogo y dialéctica no son términos sinónimos.

Tampoco se puede establecer una evolución lineal, en la historia de la novela, desde el monólogo al diálogo, o desde Mateo Alemán

34 Uno de los últimos artículos sobre el tema es el de JAVIER Blasco, «La compartida responsabilidad de la 'escritura desatada' del Quijotex, Criticón, 46, $1989,41-62$.

35 Carlos Blanco Aguinaga, «Cervantes y la picaresca: sobre dos tipos de realismow, NRFH, XI, 1957, 313-42; MARCEL BATAILLON: "Relaciones literarias", en Suma cervantina, ed. J. B. Avalle-Arce y E. C. Riley. London, Temesis, 1973, pp. 231-2 y passim.

36 Véase el comentario de RUTH El SAFFAR, "La función del narrador ficticio en Don Quijote», en El "Quijote», ed. George Haley. Madrid, Taurus, 1980, pp. 291-2.

37 Véase Michel Moner, Cervantes conteur, pp. 242-3. Sobre las mixtificaciones retónicas del vicio frente a la virtud, o viceversa, DOMINGO YNDURÁIN, «El vaivén de la virtudx. Aproximación a San Juan de la Cruz Las letras del verso. Madrid, Cátedra, 1990, pp. 209-32.

36 Véase Juan Bautista Avalle-ARce, «El nacimiento del héroew, Don Quijote como forma de vida. Valencia, Fundación Juan March-Castalia, 1976, pp. 60-97.

30 «De Alemán a Cervantes: monólogo y diálogow, en Homenaje al Prof. Muñoz Cortés. Murcia, Universidad, 1976-77, vol. II, pp. 713-29. 
a Cervantes. Hay diversas tradiciones novelísticas, y no todas pueden definirse como la "categoría del diálogo" ${ }^{40}$. Sin embargo, de aceptarse la sentencia de Ortega y Gasset, cabría añadir que el diálogo de la novela, en términos genéricos, es diferente de los diálogos que hay en la tradición literaria anterior, incluidos los de la Celestina y los del teatro. Es decir que, como categoría del diálogo, la novela nace con Don Quijote.

JESÚS GÓMEZ

Universidad Autónoma de Madrid

- Comenta Gonzalo Sobejano (art. cit., p. 728): «Dijo Ortega y Gasset que el Quijote era 'un conjunto de diálogos' y que la novela es la categoría del diálogo', como de la pintura lo es la luz. Puesta la mirada en el Quijote y en su magnífica herencia del siglo XXX (Balzac, Stendhal, Dickens, Dostoievski, Galdós) bien podria definirse la novela como la categoría del diálogo. Si se atiende a otros modernos impulsores del género (Flaubert, Clarín, Proust, Joyce, Faulkner, Beckett) muy bien pudiera pensarse que la novela fuese la categoria del monólogon. 